\title{
Casein kinase II regulation of yeast TFIIIB is mediated by the TATA-binding protein
}

\author{
Ataollah Ghavidel and Michael C. Schultz ${ }^{1}$ \\ Department of Biochemistry, University of Alberta, Edmonton, Alberta, Canada T6G 2H 7
}

\begin{abstract}
The highly conserved protein kinase casein kinase II (CKII) is required for efficient Pol III transcription of the tRNA and 5S rRNA genes in Saccharomyces cerevisiae. Using purified factors from wild-type cells to complement transcription extracts from a conditional lethal mutant of CKII we show that TFIIIB is the CKII-responsive component of the Pol III transcription machinery. Dephosphorylation of TFIIIB eliminated its ability to complement CKII-depleted extract, and a single TFIIIB subunit, the TATA-binding protein (TBP), is a preferred substrate of CKII in vitro. Recombinant TBP purified from Escherichia coli is phosphorylated efficiently by CKII and, in the presence of a limiting amount of CKII, is able to substantially rescue transcription in CKII-deficient extract. Our results establish that TBP is a key component of the pathway linking CKII activity and Pol III transcription and suggest that TBP is the target of a CKII-mediated regulatory mechanism that can modulate Pol III transcription.
\end{abstract}

[Key Words: Transcription; RN A polymerase III; TFIIIB; TBP; casein kinase II]

Received July 10, 1997; revised version accepted September 5, 1997.

The genes transcribed by RNA polymerase III (Pol III), like many transcribed by RN A Pol II, are strictly regulated according to cell cycle position, growth rate, and developmental phase (Hoeffler et al. 1988; Tower and Sollner-Webb 1988; Wolffe and Brown 1988; White et al. 1989, 1995a,b; Hartl et al. 1993; Reynolds 1993; Gottesfeld et al. 1994; Sethy et al. 1995). Pol III transcription also responds to a number of pathol ogical conditions. For example, oncogenic transformation is generally associated with increased Pol III transcription (discussion in White et al. 1990, 1996). The regulation of class III gene expression operates principally at the level of the transcription initiation machinery, which includes three fundamental protein components, RNA Pol III, TFIIIB, and TFIIIC (for review, see Geiduschek and Kassavetis 1992; Willis 1993). TFIIIB is a complex of the highly conserved TATA-binding protein (TBP) with at least two other proteins generally referred to as TBP-associated factors or TAFs. There are two Pol III-specific TAFs in Saccharomyces cerevisiae (TFIIIB ${ }_{70} /$ Brflp and TFIIIB ${ }_{90} /$ Tfc5p; gene identification summarized in Kumar et al. 1997), and one of these, Brflp, is conserved in human (Wang and Roeder 1995). TFIIIC, composed of six subunits in yeast, is the principal sequence-specific DNAbinding component of the Pol III machinery (for review, see Geiduschek and Kassavetis 1992; Willis 1993).

TFIIIB and TFIIIC are the primary targets of the regu-

${ }^{1}$ Corresponding author.

E-MAIL michael.schultz@ual bertaca; FAX (403) 492-9556. latory mechanisms that affect Pol III transcription. For example, TFIIIB is the target of the mechanism that represses Pol III transcription in metaphase extracts from Xenopus eggs (Hartl et al. 1993; Gottesfeld et al. 1994; Leresche et al . 1996) and mammal ian tissue culture cel Is (White et al. 1995b). In mammalian cells and yeast both TFIIIB and TFIIIC are limiting in stationary phase (Tower and Sollner-Webb 1988; Sethy et al. 1995) and TFIIIC is limiting early in $\mathrm{S}$ phase in mammalian cells (White et al. 1995a). In the case of TFIIIB, the regulatory functions of individual subunits are becoming clear. The TBP subunit of Xenopus TFIIIB may be repressed in metaphase extracts (Leresche et al. 1996), and TBP is limiting for Pol III transcription in Drosophila tissue culture cells (Trivedi et al. 1996). In mammalian cells the metaphase silencing of Pol III transcription results from repression of one or more of the Pol III TAFs (White et al. 1995b), and a decline in Brflp expression partly accounts for decreased TFIIIB activity in the stationary phase of yeast (Sethy et al. 1995). Consi dering these results, there has been intense interest in identifying the signaling pathways that impinge on the Pol III transcription machinery. A substantial body of evidence suggests that these signaling pathways involve protein phosphorylation events. As a result, protein kinases and phosphatases involved in the regulation of Pol III transcription are actively being sought.

One highly conserved $\mathrm{S} / \mathrm{T} / \mathrm{Y}$ protein kinase implicated in the regulation of Pol III transcription is casein kinase II (CKII; for review, see Pinna 1990; Tuazon and 
Traugh 1991; Litchfield and Lüscher 1993; Allende and Allende 1995). The CKII holoenzyme, a heterotetramer of two catalytic $\alpha$ subunits $\left(\alpha \alpha^{\prime}\right)$ and two noncatalytic $\beta$ subunits $\left(2 \beta\right.$ or $\left.\beta \beta^{\prime}\right)$, is general ly implicated in transcriptional regulation by the observation that RN A synthesis is severely inhibited when a temperature-sensitive mutant of yeast CKII $\alpha^{\prime}$ is shifted to the restrictive temperature (Hanna et al. 1995). We further reported that efficient Pol III transcription of the yeast 5S rRNA and tRN A genes requires CKII, and we have presented evidence suggesting that CKII activity is required for efficient initiation (Hockman and Schultz 1996). Taking advantage of the ability to prepare a CKII- and Pol III-deficient extract from the yeast temperature-sensitive mutant of CKII, we have pursued a biochemical approach ai med at identifying the component of the Pol III transcription machinery that responds to CKII inactivation. We show that the transcription factor TFIIIB is specifically defective in extracts depleted of CKII and that TBP, the central transcription factor in the nucleus, is the target of CKII among the subunits of TFIIIB.

\section{Results}

Transcription in CKII-deficient extract is rescued by TFIIIB

Two isogenic strains, designated CKA2 and $\mathrm{cka}^{\mathrm{ts}}$ (temperature-sensitive), were used in this study. These strains differ only in the sequence of the CKA2 gene (encoding CKII $\alpha^{\prime}$ ), which is wild type in CKA2 but carries mutations that confer a temperature-sensitive-lethal phenotype in strain cka2 ${ }^{\text {ts }}$ (Hanna et al. 1995). Whether the starting material is lysed cells (Hockman and Schultz 1996) or isolated nuclei (not shown), CKII activity in transcription extracts from strain $\mathrm{Cka2}^{\text {ts }}$ is $\sim 20$-fold lower than wild type. To identify the CKII-responsive component of the Pol III transcription machinery, active transcription factors purified from wild-type extract were added to $\mathrm{cka}^{\text {ts }}$ extract with low CKII activity and impaired specific transcription. Initially we prepared two complementing fractions from wild-type cells, one enriched in Pol III/TFIIIC (fraction P/C) and another enriched in TFIIIB (Fig. 1A). Both wild-type and $\mathrm{cka2}^{\text {ts }}$ extracts were responsive to TFIIIB, although the magnitude of the response differed significantly between the extracts. TFIIIB slightly stimulated transcription in wild-type extract (Fig. 1B, lanes 1-4), in agreement with previous reports (see Sethy et al. 1995). In contrast, TFIIIB strongly stimulated transcription in $\mathrm{cka2}^{\text {ts }}$ extract; the purified factor was able to restore activity in the mutant to that of wild type supplemented with TFIIIB (Fig. 1B, lanes 5-8). Based on this result we propose that the defect in $\mathrm{Cka2}^{\text {ts }}$ extract results primarily from inactivation of TFIIIB.

This conclusion is supported by complementation experiments using the P/C (Pol III/TFIIIC) fraction. Titration of fraction $\mathrm{P} / \mathrm{C}$ into wild-type extract was either without effect (not shown) or very slightly stimulated transcription (Fig. 1C, lanes 1-4). The P/C fraction slightly stimulated $\mathrm{cka}^{\mathrm{ts}}$ extract, but it did not restore
A
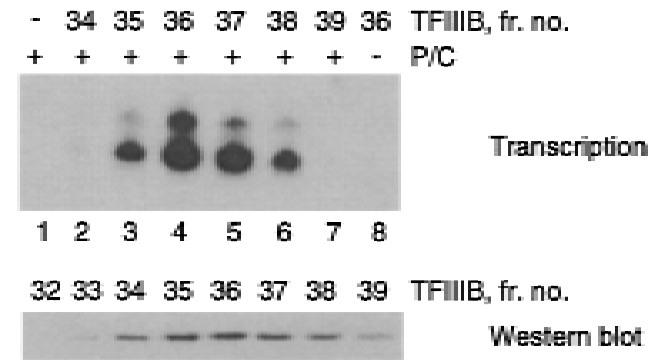

B

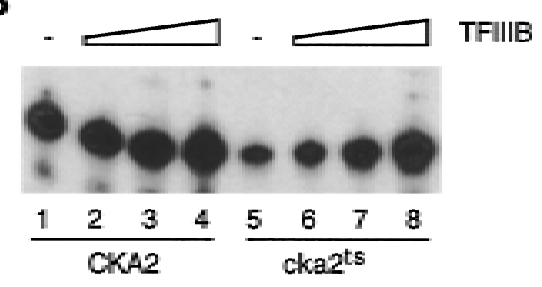

C

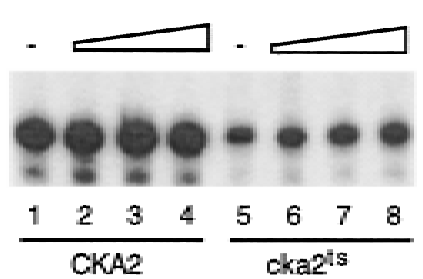

Figure 1. Pol III transcription in CKII-deficient whole cell extract is rescued by TFIIIB. (A) (Top) The P/C and TFIIIB fractions reconstitute Pol III transcription. tRNA transcription (20 ng template/reaction) was assayed using $4 \mu \mathrm{l}$ of $\mathrm{P} / \mathrm{C}$, either added to $10-\mu \mathrm{l}$ aliquots of fractions from the hydroxyapatite column used to purify TFIIIB (Ianes 1-7), or on its own (lane 8). (Bottom) The peak of TFIIIB activity obtained by hydroxyapatite chromatography corresponds to the peak of TBP. Immunobl ot of TFIIIB fractions (12- $\mu$ l aliquots) using antiserum raised against recombinant TBP. (B) TFIIIB $(0,0.4,1$, and $2.5 \mu \mathrm{l})$ slightly stimulates $5 S$ rRN A transcription in CKA2 extract (lanes 1-4) and fully restores transcription in $\mathrm{cka2}^{\text {ts }}$ extract (lanes 5-8). (C) The P/C fraction $(0,0.8,2$ and $5 \mu \mathrm{l})$ does not significantly stimulate $5 \mathrm{~S}$ rRN A transcription in CKA2 or $\mathrm{Cka}^{\mathrm{ts}}$ extract. The reactions in $B$ and $C$ used $60 \mu \mathrm{g}$ of extract and plasmid pY5S at $400 \mathrm{ng} /$ reaction.

transcription to the wild-type level (Fig. 1C, lanes 5-8). This result suggests that neither RN A Pol III nor TFIIIC is significantly affected by the loss of CKII activity.

The Pol III transcription machinery can be partially purified by DEAE chromatography (Riggs and Nomura 1990). This procedure provides a $300 \mathrm{~mm} \mathrm{KCl}$ cut from $D E A E$, referred to as fraction $D 300$, in which the difference in transcription capacity between wild-type and cka2 ${ }^{\text {ts }}$ extracts is accentuated (Fig. 2A). In view of the results in Figure 1, we reasoned that a cka2 ${ }^{\text {ts }}-\mathrm{D} 300$ fraction that is severely impaired compared to the wild type fraction (prepared in parallel) would be highly sensitive to the addition of TFIIIB. TFIIIB massively stimulates transcription in $\mathrm{cka2}^{\text {ts }}$-D 300 (Fig. 2B). To show that this stimulatory activity corresponds to TFIIIB we supplemented $c k a 2^{\text {ts }}-D 300$ with al iquots of fractions from the 


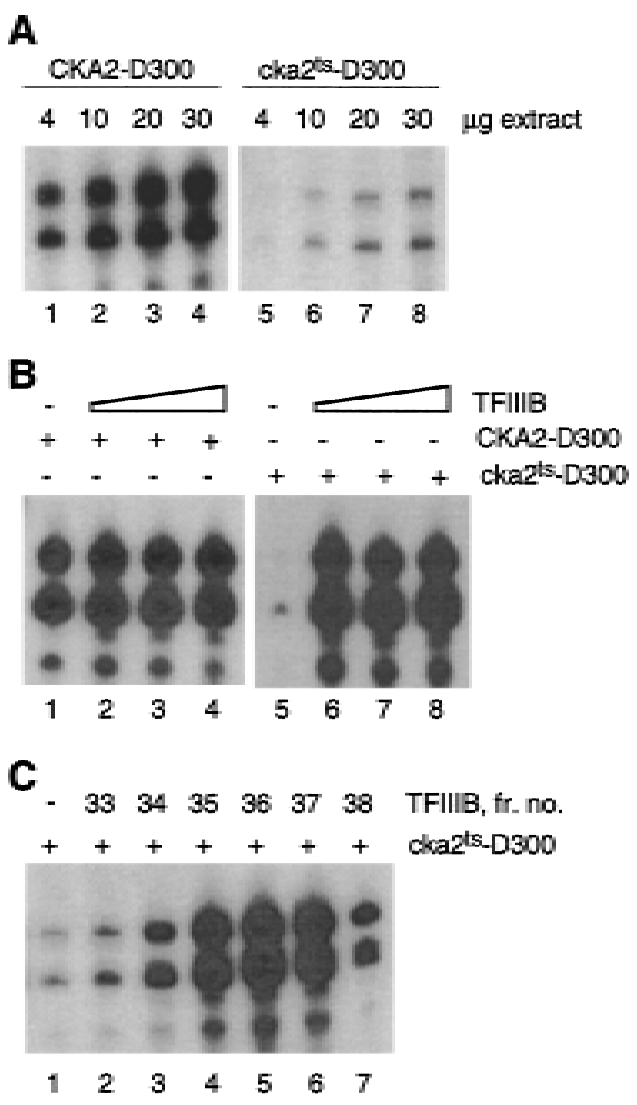

Figure 2. The transcription defect in CKII-depleted extract is preserved after partial purification of the Pol III transcription machinery and is fully rescued by TFIIIB. (A) tRN A transcription in the $300 \mathrm{~mm} \mathrm{KCl} \mathrm{DEAE} \mathrm{fraction} \mathrm{from} \mathrm{CKA2} \mathrm{and} \mathrm{cka}^{\mathrm{ts}}$ extracts. (B) TFIIIB marginally stimulates tRN A transcription in CKA2-D300 (lanes 1-4) and fully restores transcription in $\mathrm{cka2}^{\text {ts }}$-D300 (lanes 5-8). The reactions received $0,2,5$, or $10 \mu \mathrm{l}$ of hydroxyapatite TFIIIB and $13 \mu \mathrm{g}$ of D300 fraction. (C) The peak of TFIIIB activity (fraction 36, Fig. 1A) corresponds to the peak of activity capable of rescuing transcription in $\mathrm{cka}^{\text {ts }}$ D300 (lane 5). Transcription was assayed using $13 \mu \mathrm{g}$ of cka2 ${ }^{\mathrm{ts}}$ D 300 added to $10-\mu$ l al iquots of fractions from the hydroxyapatite column used to purify TFIIIB. The template was at $20 \mathrm{ng} /$ reaction.

hydroxyapatite column used for TFIIIB purification. The activity that stimulates $\mathrm{cka2}^{\mathrm{ts}}-\mathrm{D} 300$ occurs in fractions 34-38, with the peak in fraction 36 and no activity in fraction 39 (Fig. 2C). This profile exactly corresponds to the profile of TFIIIB activity that complements the wildtype $P / C$ fraction (Fig. IA).

The results of adding P/C to whole cell extracts of CKA2 and $\mathrm{cka2}^{\text {ts }}$ suggest that if either Pol III or TFIIIC is inactivated in $\mathrm{cka}^{\mathrm{ts}}$, the effect is minimal. This interpretation is supported by the results obtained when the $\mathrm{P} / \mathrm{C}$ fraction is titrated into the respective D300 fractions: $\mathrm{P} / \mathrm{C}$ produced a slight inhibition of transcription in CKA2-D300 (Fig. 3A, lanes 1-3) and marginally stimulated cka2 ${ }^{\text {ts }}$-D 300 (lanes 4-6). In further support of the conclusion that neither Pol III nor TFIIIC is significantly inhibited in $\mathrm{Cka2}^{\mathrm{ts}}$, we observed that bulk Pol III activity (elongation) and DNA binding by TFIIIC are similar in CKA 2 and $c k a 2^{\text {ts }}$ extracts. Bulk Pol III activity, assayed using nonspecific duplex DN A as the template, was virtually identical in CKA2 and $\mathrm{cka2}^{\text {ts }}$ whole cell extracts (Fig. 3B), as in nuclear extracts and the D300 fractions (data not shown). Based on previous work (Kassavetis et al. 1989) we established a DN A-binding assay for TFIIIC present in the D300 fraction (Fig. 3C, lanes 1-9). Using this assay we could not detect any difference in DNA binding by TFIIIC in CKA 2 and $\mathrm{cka}^{2 \mathrm{ts}}$ extracts (Fig. 3C, lanes 10,11). Taken together, the results in Figures 1-3 suggest that inactivation of CKII results in specific inactivation of the TFIIIB component of the Pol III transcription machinery.

TFIIIB does not contain an activity that can restore the enzymatic function of temperature-sensitive CKII

Although the fraction that stimulates $\mathrm{cka}^{2 \mathrm{ts}}$ extract precisely coelutes with TFIIIB, our results do not rule out the possibility that the TFIIIB fraction contains a factor that restores CKII activity in $\mathrm{cka2}^{\text {ts }}$ extract (or the D300 fraction). This factor could be CKII itself or a CKII activator (for review, see Tuazon and Traugh 1991; Allende and Allende 1995). We tested for CKII in the TFIIIB fraction using the peptide phosphorylation assay. CKII activity was measured in $3.2 \mu \mathrm{l}$ of TFIIIB, an amount that fully rescues transcription in $\mathrm{Cka2}^{\mathrm{ts}}-\mathrm{D} 300$ (Fig. 2B). These measurements are compared to the CKII activity in $15 \mu \mathrm{g}$ of wild-type D300 fraction (see Fig. 2A). As shown, TFIIIB contains $\measuredangle 5 \%$ of the CKII activity measured in the CKA2-D300 fraction (Fig. 4A). The content of CKII in the TFIIIB fraction was also assessed by immunoblotting using an antiserum that specifically recognizes the $\beta^{\prime}$ subunit of yeast CKII. We could not detect CKII $\beta^{\prime}$ in amounts of TFIIIB similar to those used for the reconstitution of transcription (Fig. 4B), confirming the result obtained by assaying kinase activity. Therefore, CKII is substantially depleted in the fractions used for reconstitution of transcription.

To test whether the TFIIIB fraction contained an activity that could stimulate the temperature-sensitive CKII, we assayed bulk CKII activity in the D300 fractions with and without added TFIIIB (Fig. 4C). Increased CKII activity can be measured when TFIIIB is added to cka2 ${ }^{\text {ts }}$-D300; however, the activity remains 10 -fold lower than in the equivalent reaction in which TFIIIB is added to CKA2-D300. Furthermore, transcription in cka2 ${ }^{\mathrm{ts}}-\mathrm{D} 300$ is not stimulated when purified CKII is used to raise the bulk CKII activity to the level observed upon addition of TFIIIB (not shown). We conclude that the transcription machinery responds directly to CKII depletion and that TFIIIB is the component of the transcription machinery that is inactivated when CKII is depleted.

TFIIIB must be phosphorylated to restore transcription in $\mathrm{cka} 2^{\mathrm{ts}}$ extract

The results presented above demonstrate that TFIIIB responds to changes in CKII activity. This raises the pos- 
Regulation of TATA-binding protein by CKII

A

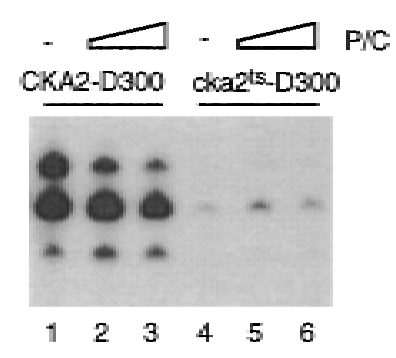

B

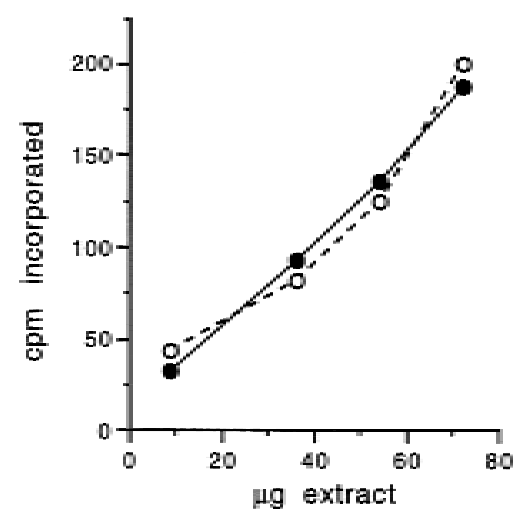

C

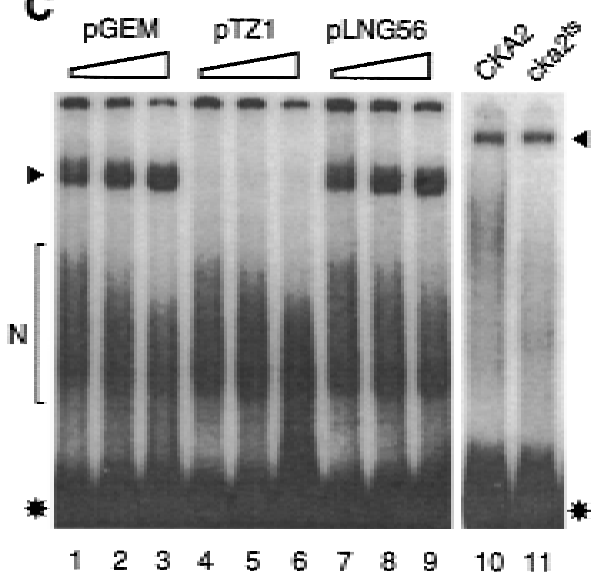

Figure 3. The transcription defect observed after partial purification of the Pol III transcription machinery from CKII-depleted extract is not due to inactivation of Pol III or TFIIIC. (A) The P/C fraction inhibits tRN A transcription in the $300 \mathrm{mM} \mathrm{KCI} \mathrm{DEAE} \mathrm{fraction} \mathrm{from}$ CKA2 extract (lanes 1-4) and only marginal ly stimulates transcription in the corresponding fraction from cka2 ${ }^{\text {ts }}$ extract (lanes 5-8). All reactions received $13 \mu \mathrm{g}$ of the D 300 fraction, $20 \mathrm{ng}$ of template, and 0,4 , or $8 \mu \mathrm{l}$ of P/C. (B) Bulk Pol III activity in CKA2 (-) and cka2 ${ }^{\mathrm{ts}}$ (O) whole cell extracts, expressed as counts per $\min (\mathrm{cpm})$ incorporated during a 25 -min reaction at room temperature. (C) TFIIIC DN A-binding activity in the D300 fraction of wild-type extract (3.5 $\mu \mathrm{g}$; lanes 1-9). The probe was an end-label ed restriction fragment from pTZ1 (4.4 ng/reaction). Specificity of binding was established using increasing amounts (700, 1000, 1700 ng) of nonspecific competitor (pGEM 3), specific competitor (pTZ1), or a binding site mutant competitor (pLN G56). Lanes 10 and 11 compare TFIIIC binding in the D300 fractions from CKA2 and $\mathrm{cka2}^{\text {ts }}$ cells. The specific TFIIIC shift (arrowheads) and free probe (asterisks) are indicated. Some nonspecific binding to probe DNA was observed in all experiments (N).

sibility that direct CKII phosphorylation of TFIIIB is important for the activity of TFIIIB. We therefore tested whether dephosphorylation of TFIIIB affects its ability to stimulate transcription in $\mathrm{cka2}^{\text {ts }}$ extract (Fig. 5). TFIIIB was treated with phosphatase in the presence or absence of the phosphatase inhibitor sodium vanadate and added to $\mathrm{cka2}^{\text {ts }}$ nuclear extract (in which CKII activity is $<2.5 \%$ of wild type; data not shown). TFIIIB retained its capacity to stimulate $\mathrm{cka}^{\mathrm{ts}}$ extract when incubated with phosphatase in the presence of sodium vanadate (cf. lanes $1,3,6,7)$. In contrast, TFIIIB treated in turn with phosphatase and then sodium vanadate was unable to stimulate $\mathrm{cka2}^{\text {ts }}$ extract (cf. lanes 1,3,4,5). Because sodium vanadate does not affect transcription on its own (lane 8), we conclude that TFIIIB must be phosphorylated to restore transcription to $\mathrm{cka2}^{\mathrm{ts}}$ extract.

\section{A single subunit of TFIIIB, the TBP, is phosphorylated by CKII}

Four observations suggest that phosphorylation of TFIIIB by CKII can be limiting for transcription in wild-type extracts: (1) TFIIIB is limiting in wild-type extracts (Fig. 1B, lanes 1-4); (2) TFIIIB activity declines when CKII activity decl ines (Fig. 1B, lanes 5-8); (3) TFIIIB I oses transcriptional activity when it is dephosphorylated (Fig. 5); (4) CKII stimulates transcription in some whole cell extracts from CKA2 cells, although our CKII preparations do not support transcription on their own (not shown) and do not contain TFIIIB as assayed by immunoblotting (Fig. 6). These observations suggest that CKII phosphoryIation of a TFIIIB subunit is limiting for TFIIIB activity and, therefore, that a component of the wild-type TFIIIB fraction may be a substrate for in vitro phosphorylation by CKII. Likely substrates would include the TFIIIB subunits TBP, Brf1p, and TFc5p, respectively of approximate molecular masses 29,70 , and $90 \mathrm{kD}$. To examine the CKII phosphorylation of TFIIIB, the Cibachron blue fraction was incubated with CKII in the presence of $[\gamma$ ${ }^{32} \mathrm{P}$ ]GTP as the phosphate donor (Fig. 7A ). GTP was chosen because it is an efficient phosphate donor in reactions catalyzed by CKII but not most other protein kinases. The reaction products were analyzed by immunoblotting using a chemiluminescence detection system. The short exposures appropriate for the chemiluminescence assay were insufficient to detect the signal from the ${ }^{32} \mathrm{P}$-label ed proteins. Following immunodetection the membrane was stripped of antibody and then exposed to film to detect the ${ }^{32} \mathrm{P}$ signal.

When incubated al one, yeast CKII autophosphorylates its $\beta$ and $\beta^{\prime}$ subunits (Fig. 7A, lane 1; Bidwai et al. 1994). TFIIIC does not contain significant GTP-dependent protein kinase activity on its own, and when used as a substrate for CKII only minor bands other than the CKII $\beta$ and $\beta^{\prime}$ are labeled (Fig. 7A, lane 2,3). Although some components of the TFIIIB fraction are labeled when TFIIIB is incubated on its own, these products are not detected (Fig. 7A, lane 4) except in longer exposures of the film (see bel ow). On the other hand, when TFIIIB is used as a substrate for CKII, a single band in addition to the subunits of CKII is heavily label ed (Fig. 7A, Iane 5). This band migrates at $\sim 29 \mathrm{kD}$, similar to the molecular mass of yeast TBP (yTBP). The possibility that the labeled 29-kD band is TBP was examined by immunoblot- 
A

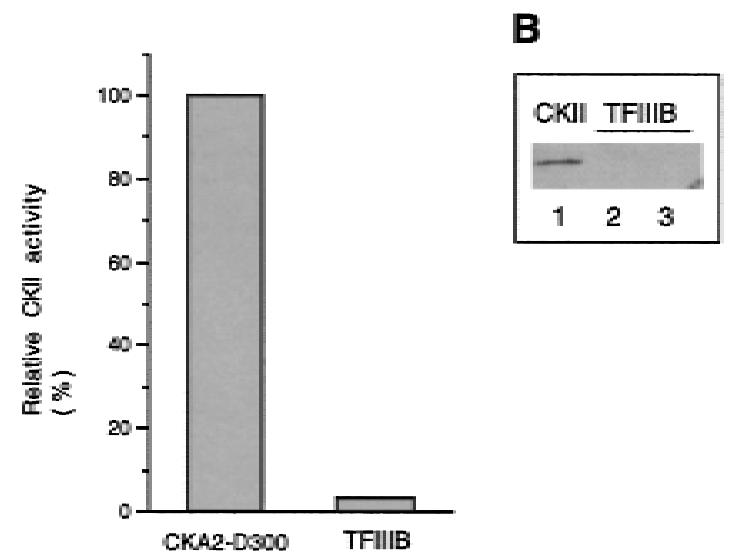

C

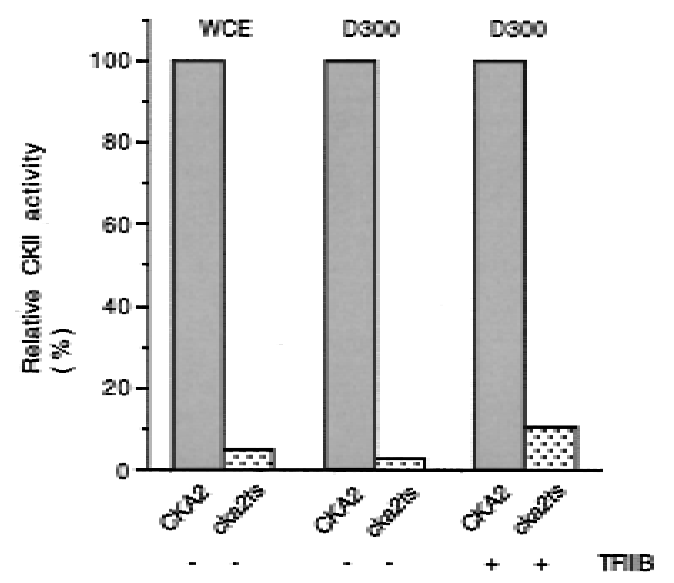

Figure 4. Rescue of transcription by TFIIIB does not involve restoration of CKII activity. (A) The TFIIIB fraction does not contain a significant amount of CKII activity. Bulk CKII activity is compared in $15 \mu \mathrm{g}$ of CKA2-D300 extract (see Fig. 2A) and 4 $\mu \mathrm{l}$ of hydroxyapatite TFIIIB. CKII activity is expressed as a percentage of activity in $15 \mu \mathrm{g}$ of CKA2-D300 (arbitrarily assigned the value of $100 \%$ ). (B) The TFIIIB fraction does not contain a significant amount of the $\beta^{\prime}$ subunit of CKII. Analysis of the TFIIIB fraction was performed by immunoblotting with a polyclonal antiserum raised against a carboxy-terminal peptide of yeast $\beta^{\prime}$. (Lane 1) Purified CKII (1 $\left.\mu \mathrm{l}\right)$; (lane 2) hydroxyapatite TFIIIB (15 $\mu \mathrm{l})$; (lane 3) Cibachron blue TFIIIB (15 $\mu \mathrm{l})$. (C) TFIIIB does not contain an activity that can restore the enzymatic function of temperature-sensitive CKII. Bulk CKII activity is expressed relative to wild type, which is arbitrarily assigned the value of $100 \%$. The reactions used $6 \mu \mathrm{g}$ of whole cell extract (WCE), $15 \mu \mathrm{g}$ of D300, and $4 \mu \mathrm{l}$ of hydroxyapatite TFIIIB.

ting using a yT BP antiserum (Fig. 7B). As expected, TBP is detected in the TFIIIB (lanes 4,5) but not the TFIIIC fraction (lanes 2,3). Furthermore, the protein labeled when TFIIIB is phosphorylated with CKII exactly comigrates with the band that reacts with the TBP antiserum. We also find that the labeled $29-\mathrm{kD}$ band comigrates with recombinant TBP run in parallel and detected by silver staining or immunoblotting (not shown).

We were surprised to observe prominent labeling of only one polypeptide among those present in the TFIIIC

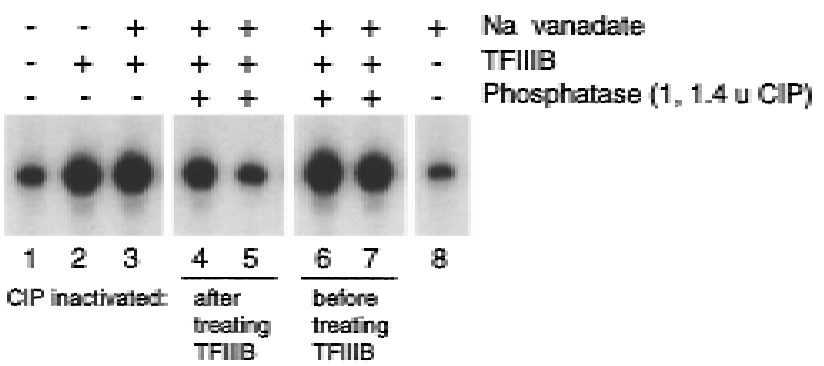

Figure 5. TFIIIB must be phosphorylated to restore transcription in $\mathrm{cka}^{\text {ts }}$ extract. TFIIIB was treated with phosphatase (CIP) in the presence or absence of sodium vanadate and then added to $\mathrm{cka2}^{\text {ts }}$ nuclear transcription extract. The final composition of each reaction is indicated in the panel above the autoradiograph; the timing of CIP inactivation by sodium vanadate is indicated below the lane numbers. Plasmid pY $5 \mathrm{~S}$ was used as the template at $400 \mathrm{ng} /$ reaction.

and TFIIIB fractions, as our most purified TFIIIC and TFIIIB preparations contain $\sim 30$ and 20 polypeptides, re spectively, and many of the nine proteins comprising TFIIIC and TFIIIB contain CKII consensus sites (Hockman and Schultz 1996). N onetheless, only TBP is significantly labeled by CKII. We conclude that the in vitro phosphorylation of TFIIIB-associated TBP by CKII is highly specific.

To extend the results obtained using cellular TFIIIB and purified CKII we tested whether recombinant TBP can be phosphorylated by CKII. Y east TBP was expressed in Escherichia coli and purified to $>95 \%$ homogeneity by ion exchange chromatography. Recombinant TBP, whether or not it was pretreated with phosphatase, was phosphorylated by CKII in the presence of [ $\gamma^{-32}$ P]ATP as the phosphate donor [Fig. 7C, lanes 1-5; the same result was obtained with GTP (data not shown)]. Consistent with the idea that CKII is responsible for the observed phosphorylation of cellular and recombinant TBP, phosphorylation is completely blocked by heparin, a widely used inhibitor of CKII (not shown). This observation, combined with the results in Figure 7, A and B, demonstrates that in our experiments the only component of the wild-type Pol III transcription machinery that is a good substrate for CKII is the TBP subunit of TFIIIB.
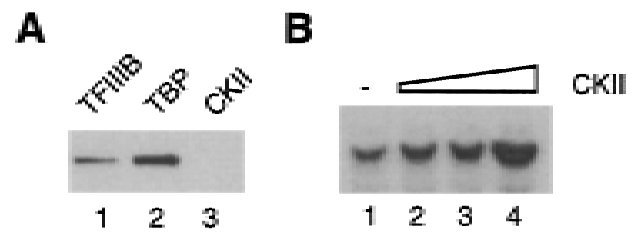

Figure 6. (A) TFIIIB does not substantially copurify with CKII. Analysis of TFIIIB by immunoblotting using a polyclonal antiserum raised against recombinant TBP. (Lane 1) Five microliters of hydroxyapatiteTFIIIB; (lane 2) $1 \mu$ l of purified TBP; (lane 3) 15 $\mu \mathrm{l}$ of purified CKII. (B) CKII can stimulate $5 \mathrm{~S}$ rRN A transcription in whole cell extract $(30 \mu \mathrm{g})$ from log phase cells. Plasmid pY5S was used as the template at $400 \mathrm{ng} /$ reaction. 


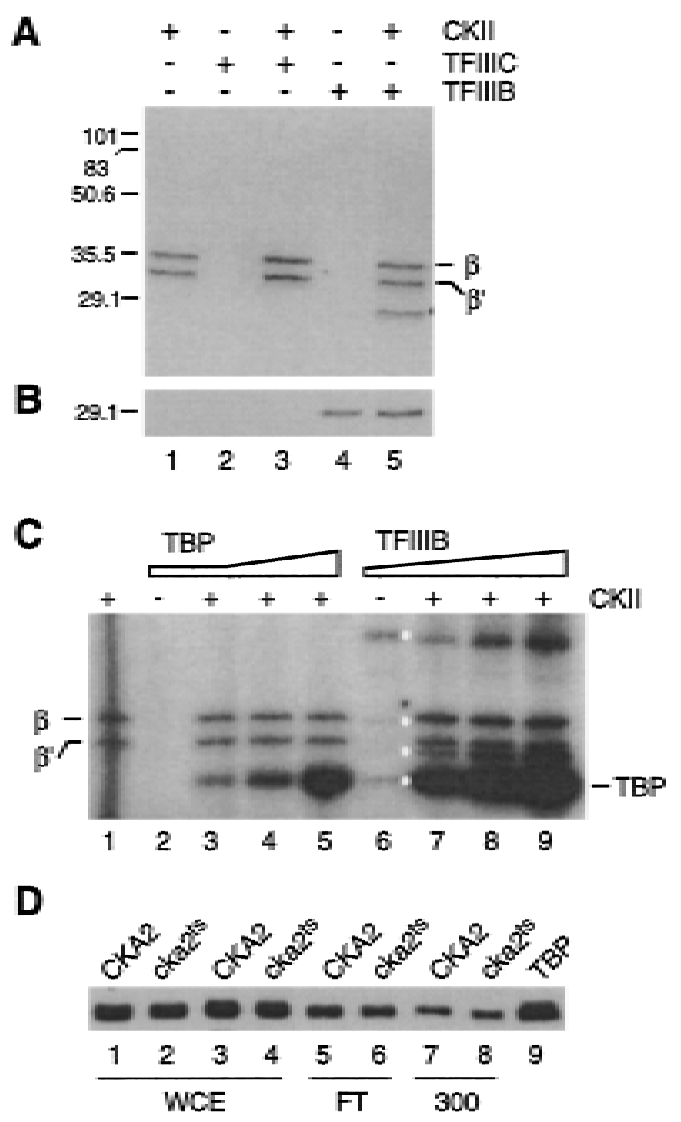

Figure 7. The TBP subunit of TFIIIB is preferentially phosphorylated by CKII. (A) Autoradiograph showing the labeled products resulting from in vitro phosphorylation of TFIIIB (10 $\mu \mathrm{l})$ and affinity-purified TFIIIC $(10 \mu \mathrm{l})$ with purified CKII $(5 \mu \mathrm{l})$. The positions of the prestained molecular weight markers and the $\beta$ subunits of CKII are shown on the left and right, respectively. (B) Immunoblotting analysis of the products in A using antiserum against TBP. As judged by the position of the markers, the immunoreactive band in lanes 4 and 5 exactly comigrates with the labeled 29-kD band in A, lane 5. (C) Recombinant TBP is phosphorylated by CKII in vitro. Reactions contained CKII on its own (lane $1 ; 0.5 \mu \mathrm{l})$, TBP on its own $(0.1 \mu \mathrm{l}$; lane 2), CKII plus increasing amounts of recombinant TBP (0.1, $0.2,0.5 \mu \mathrm{l}$; Ianes 3-5), TFIIIB on its own (Cibachron blue fraction, $12 \mu \mathrm{l}$; lane 6 ), and CKII plus increasing amounts of TFIIIB $(4,8,12 \mu \mathrm{l}$; lanes 7-9). Kinase/s in TFIIIB phosphorylate a number of proteins (white dots) that are not detected in shorter exposures (A, lane 4). (D) TBP is not depleted in whole cell extract or the DEAE fractions of $\mathrm{cka2}^{\text {ts }}$ cells. Western blot analysis of whole cell extract (WCE; $42 \mu \mathrm{g}$ per lane), the DEAE flowthrough (FT; $22 \mu \mathrm{g} /$ lane), and $300 \mathrm{~mm} \mathrm{KCl}$ fractions (300; $28 \mu \mathrm{g} /$ lane) using TBP antiserum. Recombinant TBP $(0.5 \mu \mathrm{l}$, lane 9$)$ is the marker.

Upon longer exposure of gels such as those in Figure 7 we detect a TFIIIB-associated activity that phosphorylates several proteins in the TFIIIB preparation, including TBP (Fig. 7C, Iane 6; cf. with short exposure in A, Iane 4). The level of TBP phosphorylation by the TFIIIB-associated kinase, however, is minor compared with that ob- tained when CKII is added to TFIIIB (lane 9). The molecular identity of the TFIIIB-associated kinase is not clear at the present time. It is unlikely to be a conventional form of CKII, as it is rel atively insensitive to heparin (not shown) and is not associated with a significant amount of the $\beta^{\prime}$ subunit (Fig. 4B).

Our results suggest that CKII phosphorylation of TBP increases the activity of TFIIIB. These results could be explained if the stability of TBP is affected by CKII. For example, the observation that transcription is severely impaired in $\mathrm{cka2}^{\mathrm{ts}}$-D 300 (Fig. 2A) could reflect loss of TBP during chromatography. To test whether changes in the amount of TBP could expl ain our results, we assessed the relative concentration of TBP in whole cell extract and various fractions from CKA2 and $\mathrm{cka}^{\text {ts }}$ cells by immunoblotting. We observe, in two independent sets of samples, that the concentration of TBP is virtual ly identical in CKA2 and $\mathrm{cka2}^{\text {ts }}$ whole cell extracts and fractions from DEAE (Fig. 7D). We conclude that our results cannot be explained by an effect of CKII on the stability or chromatographic properties of TBP.

TBP and a limiting amount of CKII rescues Pol III transcription in CKII-deficient extract

We next tested whether the activity of TBP as a Pol III transcription factor is influenced by CKII. This was done by supplementing nuclear transcription extract with recombinant TBP and purified yeast CKII, either al one or in combination (Fig. 8A). We observe significant stimulation of transcription in $\mathrm{cka2}^{\mathrm{ts}}$ extract by TBP alone (lanes 1-3). [Large amounts of TBP inhibit transcription (lane4), perhaps by nonspecific occlusion of the template or by squelching.] The observed stimulatory effect of TBP on its own suggests that a TBP-dependent step in transcription is impai red as a consequence of CKII depletion. The effect of adding TBP and CKII together supports this idea. By comparing lanes 1-3 with 5-7 in Figure $8 \mathrm{~A}$, it is clear that the amount of TBP required to maximally stimulate $c k a 2^{\text {ts }}$ extract is significantly low-
A

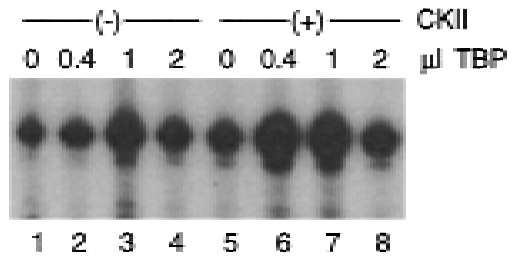

B

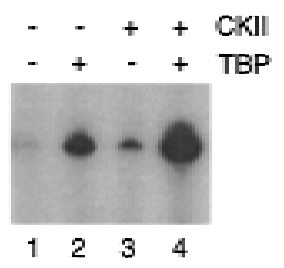

Figure 8. TBP and a limiting amount of CKII rescues pol III transcription in CKII-deficient extract. (A) N uclear extract (16 $\mu \mathrm{g}$ ) from $\mathrm{cka}^{\text {ts }}$ cells was supplemented with TBP alone (lanes 1-4) or increasing amounts of TBP in the presence of CKII (0.5 $\mu \mathrm{l}$, Ianes 6-8). The amount of CKII used in this experiment only slightly stimulated transcription on its own (cf. lanes 1 and 5). (B) The D300 fraction $(11 \mu \mathrm{g})$ from $\mathrm{cka2}^{\text {ts }}$ cells was supplemented with buffer (Iane 1$)$, TBP $(2 \mu \mathrm{l}$, lane 2$)$, CKII $(2.5 \mu l$, lane 3 ), and TBP plus CKII (lane 4). Plasmid pY5S was used as the template at $400 \mathrm{ng} /$ reaction. 
ered when TBP is added al ong with a limiting amount of CKII. Importantly, under these conditions stimulation by CKII and TBP together is significantly greater than the total stimulation by each component added indi vidually (lanes $1,2,5,6)$. The same result is obtained when TBP and CKII are added to the D300 fraction of $\mathrm{Cka}^{\mathrm{ts}}$ (Fig. 8B). These experiments demonstrate that the repression of TFIIIB resulting from inactivation of CKII can be overcome by bacterially expressed TBP in the presence of a limiting amount of CKII. Based on these results and the evidence presented in Figures 1-7 we propose that di rect CKII phosphorylation of TBP is required for efficient Pol III transcription in yeast.

\section{Discussion}

We have identified TFIIIB as the component of the Pol III transcription machinery that responds to the inhibition of CKII activity. We show further that TFIIIB must be phosphorylated to restore transcription in a CKII-depleted extract and that a combination of TBP and a limiting amount of CKII rescues transcription in a CKIIdepleted extract to a higher level than the sum of TBP and CKII added individually. We have therefore identified an effector (CKII) and target (TFIIIB/TBP) that may be components of a mechanism for regulating Pol III transcription in yeast.

\section{Regulation of TFIIIB by phosphorylation}

Previous studies using extracts from Xenopus eggs suggest that the phosphorylation status of TFIIIB is important for its activity (Hartl et al. 1993; Gottesfeld et al. 1994; Leresche et al. 1996). For example, the inactive form of TFIIIB from metaphase extracts can be activated by phosphatase treatment. Conversely, the active interphase form of TFIIIB can be inactivated by $\mathrm{p} 34^{\mathrm{cdc}}{ }^{-}$-cycl in $B$ kinase. These results demonstrate that phosphorylation can inhibit TFIIIB. Our results confirm a role for phosphorylation in the regulation of TFIIIB; however, we find that CKII phosphorylation activates rather than inhibits yeast TFIIIB. Why might opposite effects of phosphorylation on the activity of TFIIIB have been detected in Xenopus and yeast? First, the different effects of phosphorylation may be species specific. We do not favor this possibility because p34 ${ }^{\mathrm{cdc} 2}$ and CKII, the known protein kinases implicated in the regulation of TFIIIB, are highly conserved and are expressed in all cycling eukaryotic cells (for review, see N urse 1990; Allende and Allende 1995), as are two potential targets of these kinases (the TBP and Brflp subunits of TFIIIB: see introductory section). Furthermore, the unique and essential catalytic functions of $\mathrm{p} 34^{\mathrm{cdc} 2}$ and CKA1/CKA2 are also highly conserved (Lee and N urse 1987; Bidwai et al. 1992). The second and, in our view, more interesting possibility is that the regulation of TFIIIB is universally mediated by its phosphorylation and dephosphorylation and that the pattern of these events is more complex than suspected previously. For example, phosphorylation at some sites in TFIIIB might stimulate transcription, whereas phos- phorylation at other sites (possibly on different subunits) might be inhibitory. The level of activation/inhibition may vary according to the site of phosphorylation, with some inhibitory sites possibly being dominant over sites required for maximal activity. The latter scenario has been described in another context; the p34 ${ }^{\mathrm{cdc} 2}$ component of the $\mathrm{p} 34^{\text {cdc2 }}$-cyclin $B$ complex is regulated by dominant inhibitory and stimulatory phosphorylation events (for review, see King et al . 1994). These considerations suggest the working hypothesis that TFIIIB is regulated by positive and negative phosphorylation events and that CKII is involved in the positive phosphorylation event.

\section{The molecular target of CKII phosphorylation}

Our evidence indicates that the regulation of TFIIIB by CKII occurs through direct CKII phosphorylation of the TBP subunit of TFIIIB. Specifically, the observation that CKII stimulates transcription in wild-type transcription extract correlates with the finding that only one polypeptide in our wild-type TFIIIB fraction, TBP, is efficiently phosphorylated by CKII in vitro. Furthermore, a limiting amount of CKII increases the stimulation of transcription in $\mathrm{cka}^{\mathrm{ts}}$ extract by a fixed amount of TBP. Based on these results we propose that direct phosphorylation of TBP by CKII is required for efficient Pol III transcription in vitro. Consistent with this proposal, we note that $y$ TBP contains three motifs that match the CKII consensus S/T Xx acidic [the $Y$ specificity motif is not present in yTBP (Wilson et al. 1997)]. Because the amino-terminal 60 residues of yT BP are dispensable for function in vivo (Reddy and Hahn 1991), potential CKII sites in this region are unlikely to play a significant role in Pol III transcription. The remaining 180 residues of TBP contain potential CKII sites at S128 and S183. M odeling studies using the VADAR program (Wishart et al. 1994) indicate that S183, which is buried in the crystal structure of TBP (Chasman et al. 1993), is highly unlikely to be solvent exposed. This residue therefore is unlikely to be available for phosphorylation by CKII. $\mathrm{S} 128$, on the other hand, is solvent exposed, highly conserved (Kim et al. 1993), and the CKII consensus sequence at S128 encompasses a small surface of TBP that is important for Pol III transcription in vivo (Cormack and Struhl 1993; Trivedi et al. 1996). Furthermore, mutation of S128 to $\mathrm{G}$ in yeast confers a temperature-sensitive phenotype that may reflect an impairment of Pol III transcription in vivo (Cormack and Struhl 1993). These considerations, in light of the recent report that TBP is limiting for transcription in Drosophila tissue culture cells (Trivedi et al. 1996), suggest the possibility that CKII phosphorylation of TBP is required for the maintenance of efficient Pol III transcription in vivo.

\section{CKII and the regulatory mechanisms that impinge} on TFIIIB

Our work potentially relates to the mounting evidence that TFIIIB is a key target of regulatory mechanisms that 
govern the output of Pol III genes. In mammalian cells the response of the Pol III transcription machinery to a wide variety of internal and external cues is governed by mechanisms that regulate TFIIIB (see introductory section). In Xenopus the cell cycle regulation of Pol III transcription operates at the level of TFIIIB, perhaps through differential phosphorylation of its 92-kD and TBP subunits (Leresche et al. 1996). The Drosophila Pol III transcription machinery is sensitive to the cellular concentration of TBP, and in yeast the silencing of transcription in stationary phase is mainly due to an effect on TFIIIB $_{70}$ /Brflp (Sethy et al. 1995; Trivedi et al. 1996). In summary, TFIIIB is the target of a spectrum of regulatory effects that can act on distinct subunits of TFIIIB. The protein kinases involved in these diverse regulatory mechanisms remain to be fully characterized. Our results raise the possibility that CKII is one such kinase. Thus, the activity of CKII toward TBP may be regulated and therefore contribute di rectly to the regulation of Pol III transcription in vivo. On the other hand, CKII phosphorylation of TBP might be constitutive and ensure that the maximal level of Pol III transcription is achieved when the demand for Pol III products is at its peak. These hypotheses will be amenable to critical experimental analysis in yeast.

\section{Materials and methods}

Buffers

Buffers are described as follows: (YDBI) $50 \mathrm{~mm} \mathrm{KCl}, 5 \mathrm{~mm}$ EGTA, $0.05 \mathrm{~mm}$ EDTA, $2.5 \mathrm{~mm}$ DTT, $0.4 \mathrm{~mm}$ PMSF, and 20\% glycerol. (Buffer B) $1 \mathrm{~mm}$ EDTA, $1 \mathrm{~mm}$ DTT, $0.4 \mathrm{~mm} \mathrm{PMSF}$, and $20 \%$ glycerol. (Buffer L) $1 \mathrm{~mm}$ EDTA, $5 \mathrm{~mm} \mathrm{MgCl}_{2}, 2.5 \mathrm{~mm}$ DTT, $0.2 \mathrm{~mm}$ PMSF, 10\% glycerol, and 0.05\% NP-40. Buffers $Y D B I, B$ and $L$ also contained $20 \mathrm{~mm}$ HEPES-KOH (pH 7.9) and $0.3 \mu \mathrm{g} / \mathrm{ml}$ of leupeptin. (Buffer K) $0.5 \mathrm{~mm}$ DTT, $0.4 \mathrm{~mm} \mathrm{PMSF}$, $0.6 \mu \mathrm{g} / \mathrm{ml}$ of leupeptin, $0.6 \mu \mathrm{g} / \mathrm{ml}$ of pepstatin, and $20 \%$ glycerol. (Buffer T) $20 \mathrm{~mm}$ Tris- $\mathrm{HCl}$ (pH 8), 1 mm EDTA, 1 mM DTT, $1 \mathrm{~mm}$ PMSF, $2 \mathrm{~mm}$ benzamidine- $\mathrm{HCl}$, and 10\% glycerol. The concentration of $\mathrm{KCl}(\mathrm{mM})$ in buffers $\mathrm{B}, \mathrm{K}, \mathrm{L}$, and $\mathrm{T}$ is designated by the number after the letter abbreviation.

\section{Strains and extract preparation}

Extracts were prepared from S. cerevisiae strains CKA2, cka2 ${ }^{\text {ts }}$, and the protease-deficient BJ5626 (Jones 1991) grown to an OD at $600 \mathrm{~nm}$ of 1-2 (see Hockman and Schultz 1996). CKA2 and $\mathrm{Cka2}^{\text {ts }}$ were grown at room temperature, and BJ 5626 at $30^{\circ} \mathrm{C}$. Whole cell extracts were prepared after breaking the cells under liquid nitrogen, using a motorized mortar grinder for large-scale extracts (Schultz et al. 1997). N uclear extracts were prepared in parallel from strains CKA2 and $\mathrm{cka}^{\mathrm{ts}}$ according to Dunn and Wobbe (1995).

\section{Purification and assay of transcription factors from yeast}

Large-scale whole cell extracts were fractionated according to Kassavetis et al. (1989), with modifications that take into account the presence of an inhibitor that is concentrated on BioRex 70. The transcriptionally active 35\%-70\% ammonium sulfate cut ( 2.8 grams of protein) of whole cell extract ( 7 grams) was dialyzed to YDBI and applied to $140 \mathrm{ml}$ of Bio-Rex 70 (Bio-Rad).
This column was step-eluted with 100,250 , and $500 \mathrm{~mm} \mathrm{KCl}$ in YDBI. The $500 \mathrm{~mm} \mathrm{KCl}$ fraction contained all components of the Pol III transcription machinery, although it was transcriptionally inert because of an inhibitor that is separated from Pol III/TFIIIC on DEAE and from TFIIIB on hydroxyapatite. The Bio-Rex $500 \mathrm{~mm} \mathrm{KCl}$ fraction (160 mg) was dialyzed to B100 and applied to a 40-ml DEAE-Sepharose Fast Flow (Pharmacia) column equilibrated in B100; fractions were collected from the 100,300 , and $600 \mathrm{~mm} \mathrm{KCI}$ washes. TFIIIB (108 mg), el uted in the flowthrough, was dialyzed to buffer $\mathrm{K}$ containing $25 \mathrm{mM} \mathrm{KPO}_{4}$ (buffer K25). Fifty milligrams of this fraction was loaded onto a 20-ml Bio-Gel hydroxyapatite (Bio-Rad) column equilibrated in buffer K25. The column was washed with buffer $\mathrm{K} 50$ and developed with a 75-ml gradient $\left(50-300 \mathrm{mM} \mathrm{KPO}_{4}\right)$ that eluted TFIIIB at $\sim 200 \mathrm{~mm} \mathrm{KPO}_{4}$. TFIIIB fractions $(\sim 3 \mathrm{mg})$ were dialyzed against buffer B200 and applied to a 3-ml Cibacron blue-Sepharose column (Fluka). Following washing with buffer B200, TFIIIB was eluted with B1000. Pol III and TFIIIC (20 mg) eluted together in the $300 \mathrm{~mm}$ cut from DEAE. Ten milligrams of this fraction $(P / C)$ was dialyzed to buffer $L 100$, precleared with 0.6 mg of pGEM 3, and applied to a 1.1-ml TFIIIC affinity column [synthetic box $B+29-m e r$ coupled in 10 repeat fragments (average) to Sepharose CL2B (Kassavetis et al. 1989)]. The column was washed with buffer L200, and TFIIIC was eluted with L1000. Bulk Pol III activity was measured according to Schultz and Hall (1976). TFIIIB was monitored during chromatography by immunoblotting with a polyclonal antiserum against TBP (1:10,000 dilution). TFIIIB was also monitored by its ability to complement fraction $\mathrm{P} / \mathrm{C}$, which is transcriptionally inactive and devoid of TBP but enriched in bulk Pol III activity and TFIIIC DNA-binding activity. TFIIIC was monitored by its DNA-binding activity according to the method of Kassavetis et al. (1989). The Pol III machinery was obtained in a single fraction (D300) by applying whole cell extract in YDBI to a DEAESepharose Fast Flow column (Riggs and Nomura 1990). The column was washed with $90 \mathrm{~mm} \mathrm{KCl/YDBI}$, and the transcription machinery was then eluted with $300 \mathrm{~mm} \mathrm{KCl/YDBI}$.

\section{Expression and purification of recombinant TBP}

Yeast TBP was expressed in E. coli strain BL21(DE3) and purified according to a protocol developed by Steve Hahn (pers. comm.; see al so Reddy and Hahn 1991). Briefly, cells containing plasmid pSH 228 were induced with $0.4 \mathrm{~mm}$ IPTG for $2 \mathrm{hr}$. The soluble fraction resulting from sonication of cells in buffer T50 was applied to DEAE-Sepharose Fast Flow, and the flowthrough collected. This material was applied to M ono S (Pharmacia) and eluted with a $50-500 \mathrm{~mm} \mathrm{KCl}$ gradient (in buffer T). TBP was recovered in the $250-300 \mathrm{~mm} \mathrm{KCl}$ fractions.

\section{Purification of CKII and assay by peptide phosphorylation}

CKII was purified according to Bidwai et al. (1994) from cells broken under liquid nitrogen using a mortar grinder (Schultz et al. 1997). The heparin-agarose fraction of CKII (85\% pure) was used for most experiments. Peptide phosphorylation was performed as described (Hockman and Schultz 1996), except that a TCA precipitation step was introduced to remove polypeptides from the reaction mix prior to spotting onto P81 paper. This step reduces the variability between replicate assays. Specifically, $25 \mu \mathrm{l}$ reactions are stopped by adding TCA to $5 \%$, incubated on ice for $10 \mathrm{~min}$, and then spun for $5 \mathrm{~min}$ in a microcentrifuge. Twenty microliters of the supernatant is then spotted onto P81 paper and processed for scintillation counting. 
Preparation and use of CKII $\beta^{\prime}$ antiserum

A peptide (DLTKSGGFKT- $3^{\prime}$ ) corresponding to the 10 carboxyterminal residues of CKII $\beta^{\prime}$ (amino acids 219-228; Reed et al. 1994) was coupled to keyhole limpet hemacyanin (KLH) at the peptide's amino terminus and used to immunize $\mathrm{N}$ ew Zeal and white rabbits. After collecting naive serum, the rabbits were injected with $1 \mathrm{mg}$ of $\mathrm{KLH}$-conjugated peptide. The injection was repeated $2,5,9$, and 13 weeks after the first immunization; serum was screened by ELISA (Harlow and Lane 1988) using the target peptide coupled to BSA and peroxidase-conjugated AffiniPure goat anti-rabbit IgG (Jackson ImmunoResearch Labs). The reaction product was detected using a peroxidase substrate kit (Bio-Rad). A strong ELISA reaction (compared to preimmune serum) was observed using serum collected at 5, 9, and 13 weeks. The serum specifically detected CKII $\beta^{\prime}$ at a 1:2500 dilution in immunoblots.

\section{Immunoblotting}

Proteins were resolved on $12 \%$ or $15 \%$ SDS-polyacrylamide gels and el ectroblotted to nitrocellulose membrane in Tris-glycine buffer. The membranes were incubated with antiserum in $20 \%$ horse serum in TBST $(100 \mathrm{~mm}$ Tris- $\mathrm{HCl}$ at pH 7.5, $150 \mathrm{~mm}$ $\mathrm{NaCl}, 5 \mathrm{mM} \mathrm{M} \mathrm{gCl} 2,0.1 \%$ Tween 20). The immunoreactive species were detected using horseradish peroxidase-conjugated anti-rabbit antibody and the ECL chemiluminescence detection system (Amersham).

\section{In vitro kinase and phosphatase reactions}

Purified CKII was incubated with potential substrates in $20 \mu \mathrm{l}$ final volume containing $15 \mathrm{~mm}$ HEPES-KOH (pH 7.9), $130 \mathrm{~mm}$ $\mathrm{KCl}, 10 \mathrm{~mm} \mathrm{MgCl}, 2.5 \mathrm{~mm}$ EGTA, $0.2 \mathrm{~mm}$ EDTA, and $1 \mu \mathrm{l}$ $\left[\gamma^{-32} \mathrm{P}\right] \mathrm{GTP}$ or $\left[\gamma^{-32 \mathrm{P}] A T P}\right.$ (N EN ; $\left.3000 \mathrm{Ci} / \mathrm{mmole}\right)$. The reactions were performed for $15 \mathrm{~min}$ at $30^{\circ} \mathrm{C}$, stopped with SDS-PAGE loading buffer, and the products resolved as described under immunoblotting. Hydroxyapatite TFIIIB was dephosphorylated by incubation for $20 \mathrm{~min}$ at room temperature with the calf al kal ine intestinal phosphatase (Sigma) in a buffer containing 20 $\mathrm{mm}$ Tris- $\mathrm{HCl}$ (pH 8.5), $50 \mathrm{~mm} \mathrm{NaCl}, 5 \mathrm{~mm} \mathrm{M} \mathrm{gCl}, 0.1 \mathrm{~mm}$ $\mathrm{ZnCl}_{2}$, and $1 \mathrm{~mm} \mathrm{DTT}$. Sodium vanadate (Sigma) was used at 0.5 $\mathrm{mm}$.

\section{In vitro transcription reactions}

Multiple round transcription reactions were performed according to Hockman and Schultz (1996) using pY5S for 5S rRNA transcription (Schultz et al. 1992) and pTZ1, which contains the SUP4 tRN A ${ }^{T y r}$ gene, for tRN A transcription (Kassavetis et al. 1989). Details are noted in the legends to Figs. 1-3, 5, 6, and 8. The final buffer composition of all reactions in an experiment was identical. Reconstitution of transcription in $\mathrm{cka}^{\text {ts }}$ extract with CKII and TBP was performed without preincubation of CKII and TBP, as CKII phosphorylation of TBP prior to mixing with cell extract usually dampens rather than enhances the stimulation of transcription (not shown). We speculate that in a kinase reaction containing only purified TBP and CKII, phosphorylation of TBP occurs at some sites that both are not available when TBP is assembled into TFIIIB and must be unmodified for TBP to participate in transcription.

\section{Acknowledgments}

We are grateful to Darren Hockman for expert technical assistance, especially in development of the CKII assay (according to hel pful suggestions from Colin Rasmussen) and the preparation of antisera. Ron Reeder kindly provided the TBP antiserum, and plasmids pTZ1 and pLNG56 were supplied by Peter Guideschek. pSH228 was from Steve Hahn, who also advised on the purification of recombinant TBP. Max Cummings and Mike Ellison are acknowledged for the molecular modeling, and we thank Clai borne Glover III for hel pful discussions and Charl otte Spencer for comments on the manuscript. Peptides were prepared by the Alberta Peptide Institute (Edmonton), and oligonucleotides were synthesized by the DNA Core Facility, Biochemistry Department, University of Alberta. This work was supported by an establishment grant from the Alberta Heritage Foundation for M edical Research and by operating grants from the Canadian National Cancer Institute and Medical Research Council (MRC). M.C.S. is a scholar of the MRC.

The publication costs of this article were defrayed in part by payment of page charges. This article must therefore be hereby marked "advertisement" in accordance with 18 USC section 1734 solely to indicate this fact.

\section{References}

Allende, J.E. and C.C. Allende. 1995. Protein kinase CK2: An enzyme with multiple substrates and a puzzling regulation. FASEB J. 9: 313-323.

Bidwai, A.P., D.E. Hanna, and C.V.C. Glover. 1992. Purification and characterization of casein kinase II (CKII) from $\Delta \mathrm{ckal}$ $\Delta c k a 2$ Saccharomyces cerevisiae rescued by Drosophila CKII subunits. The free catalytic subunit of casein kinase II is not toxic in vivo. J. Biol. Chem. 267: 18790-18796.

Bidwai, A.P., J.C Reed, and C.V.C. Glover. 1994. Casein kinase II of Saccharomyces cerevisiae contains two distinct regulatory subunits, $\beta$ and $\beta^{\prime}$. Arch. Biochem. Biophys. 309: 348355.

Chasman, D.I., K.M. Flaherty, P.A. Sharp, and R.D. Kornberg. 1993. Crystal structure of yeast TATA-binding protein and model for interaction with DNA. Proc. Natl. Acad. Sci. 90: 8174-8178.

Cormack, B.P. and K. Struhl. 1993. Regional codon randomization: defining a TATA-binding protein surface required for RNA polymerase III transcription. Science 262: 244-248.

Dunn, B. and C.R. Wobbe. 1995. Preparation of protein extracts from yeast. In Current protocols in molecular biology (ed. F.M. Ausubel, R. Brent, R.E. Kingston, D.D. Moore, J.G. Seidman, J.A. Smith, and K. Struhl), pp. 13.13.1-13.13.9. Greene/Wiley, N ew York, NY.

Geiduschek, E.P. and G.A. Kassavetis. 1992. RN A polymerase III transcription complexes. In Transcriptional regulation (ed. S.L. McKnight and K. Yamamoto), pp. 247-280. Cold Spring Harbor Laboratory Press, Cold Spring Harbor, NY.

Gottesfeld, J.M., V.J. Wolf, T. Dang, D.J. Forbes, and P. Hartl. 1994. Mitotic repression of RNA polymerase III transcription in vitro mediated by phosphorylation of a TFIIIB component. Science 263: 81-84.

Hanna, D.E., A. Rethinaswamy, and C.V.C. Glover. 1995. Casein kinase Il is required for cell cycle progression during $\mathrm{G} 1$ and $\mathrm{G} 2 / \mathrm{M}$ in Saccharomyces cerevisiae. J. Biol. Chem. 270: 25905-25914.

Harlow, E. and D. Lane, eds. 1988. Antibodies. A laboratory manual. Cold Spring Harbor Laboratory, Cold Spring Harbor, NY.

Hartl, P., J. Gottesfeld, and D.J. Forbes. 1993. M itotic repression of transciption in vitro. J. Cell Biol. 120: 613-624.

Hockman, D.J. and M.C. Schultz. 1996. Casein kinase II is required for efficient transcription by RNA polymerase III. 
Mol. Cell. Biol. 16: 892-898.

Hoeffler, W.K., R. Kovel man, and R.G. Roeder. 1988. Activation of transcription factor IIIC by the adenovirus E1A protein. Cell 53: 907-920.

Jones, E.W. 1991. Tackling the protease problem in Saccharomyces cerevisiae. Methods Enzymol. 194: 428-453.

Kassavetis, G.A., D.L. Riggs, R. N egri, L.H. N guyen, and E.P. Geiduschek. 1989. Transcription factor IIIB generates extended DNA interactions in RNA polymerase III transcription complexes on tRNA genes. Mol. Cell. Biol. 9: 25512566.

Kim, Y., J.H. Geiger, S. Hahn, and P.B. Sigler. 1993. Crystal structure of a yeast TBP/TATA-box complex. Nature 365: 512-520.

King, R.W., P.K. Jackson, and M.W. Kirschner. 1994. Mitosis in transition. Cell 79: 563-571.

Kumar, A., G.A. Kassavetis, E.P. Geiduschek, M. Hambalko, and C.J. Brent. 1997. Functional dissection of the $B^{\prime \prime}$ component of RNA polymerase III transcription factor IIIB: a scaffolding protein with mutliple roles in assembly and initiation of transcription. Mol. Cell. Biol. 17: 1868-1880.

Lee, M.G. and P. N urse. 1987. Complementation used to clone a human homologue of the fission yeast cell cycle control gene cdc2. Nature 327: 31-35.

Leresche, A., V.J. Wolf, and J.M. Gottesfeld. 1996. Repression of RNA polymerase II and III transcription during $M$ phase of the cell cycle. Exp. Cell Res. 229: 282-288.

Litchfield, D.W. and B. Lüscher. 1993. Casein kinase II in signal transduction and cell cycle regulation. Mol. Cell. Biochem. 127/ 128: 187-199.

N urse, P. 1990 U niversal control mechanism regulating onset of M-phase. Nature 344: 503-508.

Pinna, L.A. 1990. Casein kinase 2: An "eminence grise" in celIular regulation? Biochim. Biophys. Acta 1054: 267-284.

Reddy, P. and S. Hahn. 1991. Dominant negative mutations in yeast TFIID define a bipartite DNA-binding region. Cell 65: 349-357.

Reed, J.C., A.P. Bidwai, and C.V.C. Glover. 1994. Cloning and disruption of CKB2, the gene encoding the $32-\mathrm{kD}$ a regulatory $\beta^{\prime}$-subunit of Saccharomyces cerevisiae casein kinasell. J. Biol. Chem. 269: 18192-18200.

Reynolds, W.F. 1993. The tyrosine phosphatase cdc25 selectively inhibits transcription of the Xenopus oocyte-type tRN A tyrC gene. Nucleic Acids Res. 21: 4372-4377.

Riggs, D.L and M. N omura. 1990. Specific transcription of Saccharomyces cerevisiae $35 \mathrm{~S}$ rDNA by RNA polymerase I in vitro. J. Biol. Chem. 265: 7596-7603.

Schultz, L.D. and B.D. Hall. 1976. Transcription in yeast: $\alpha-$ Amanitin sensitivity and other properties which distinguish between RNA polymerases I and III. Proc. Natl. Acad. Sci. 73: 1029-1033.

Schultz, M.C., R.H. Reeder, and S. Hahn. 1992. Variants of the TATA-binding protein can distinguish subsets of RNA polymerase I, II, and III promoters. Cell 69: 697-702.

Schultz, M.C., D.J. Hockman, T.A.A. Harkness, W.I. Garinther, and B.A. Altheim. 1997. Chromatin assembly in a yeast whole-cell extract. Proc. Natl. Acad. Sci. 94: 9034-9039.

Sethy, I., R.D. Moir, M. Librizi, and I.M. Willis. 1995. In vitro evidence for growth regulation of tRNA transcription in yeast. A role for transcription factor (TF) $I I I B_{70}$ and TFIIIC. J. Biol. Chem. 270: 28463-28470.

Tower, J. and B. Sollner-Webb. 1988. Polymerase III transcription factor B activity is reduced in extracts of growth-restricted cells. Mol. Cell. Biol. 8: 1001-1005.

Trivedi, A., A. Vilalta, S. Gopalan, and D.L. Johnson. 1996. TATA-binding protein is limiting for both TATA-containing and TATA-lacking RNA polymerase III promoters in Drosophila cells. Mol. Cell. Biol. 16: 6909-6916.

Tuazon, P.T. and J.A. Traugh. 1991. Casein kinase I and IIMultipotential serine protein kinases: Structure, function, and regulation. Adv. Second Messenger Phosphoprotein Res. 23: 123-164.

Wang, Z. and R.G. Roeder. 1995. Structure and function of a human transcription factor TFIIIB subunit that is evolutionarily conserved and contains both TFIIB- and high-mobilitygroup protein 2-related domains. Proc. Natl. Acad. Sci. 92: 7026-7030.

White, R.J., D. Stott, and P.W. Rigby. 1989. Regulation of RN A polymerase III transcription in response to F9 embryonal carcinoma stem cell differentiation. Cell 59: 1081-1092.

White, R.J., D. Stott, and P.W. Rigby. 1990. Regulation of RNA polymerase III transcription in response to Simian virus 40 transformation. EMBO J. 9: 3713-3721.

White, R.J., T.M. Gottlieb, C.S. Downes, and S.P. Jackson. 1995a. Mitotic regulation of a TATA-binding-protein-containing complex. Mol. Cell. Biol. 15: 1983-1992.

White, R.J., T.M. Gottlieb, C.S. Downes, and S.P. Jackson. 1995b. Cell cycle regulation of RNA polymerase III transcription. Mol. Cell. Biol. 15: 6653-6662.

White, R.J., D. Trouche, K. M artin, S.P. Jackson, and T . Louzarides. 1996. Repression of RN A polymerase III transcription by the retinoblastoma protein. Nature 383: 88-90.

Willis, I.M. 1993. RN A polymerase III. Genes, factors and transcriptional specificity. Eur. J. Biochem. 212: 1-11.

Wilson, L.K., N. Dhillon, J. Thorner, and G.S. Martin. 1997. Casein kinase II catalyzes tyrosine phosphorylation of the yeast nucleolar immunophilin Fpr3. J. Biol. Chem. 272: 12961-12967.

Wishart, D.S., L. Willard, F.M. Richards, and B.D. Sykes. 1994. VADAR: A comprehensive program for protein structure evaluation. Version 2.1. University of Alberta, Edmonton, Canada.

Wolffe, A.P. and D.D. Brown. 1988. Developmental regulation of two 5 S ribosomal RN A genes. Science 241: 1626-1632. 


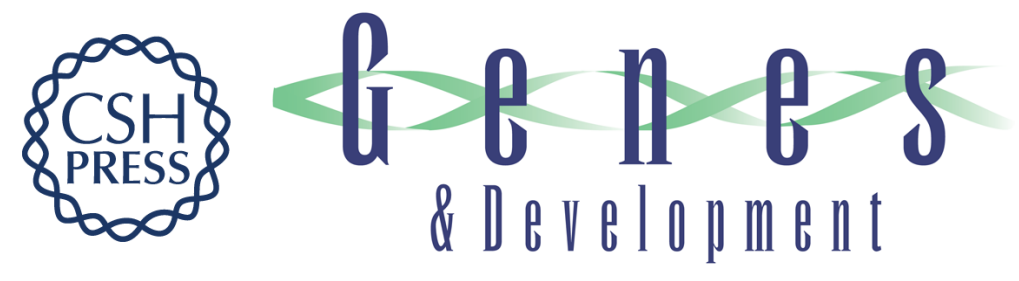

\section{Casein kinase II regulation of yeast TFIIIB is mediated by the TATA-binding protein}

Ataollah Ghavidel and Michael C. Schultz

Genes Dev. 1997, 11:

Access the most recent version at doi:10.1101/gad.11.21.2780

References

This article cites 39 articles, 21 of which can be accessed free at: http://genesdev.cshlp.org/content/11/21/2780.full.html\#ref-list-1

License

Email Alerting

Receive free email alerts when new articles cite this article - sign up in the box at the top Service right corner of the article or click here.

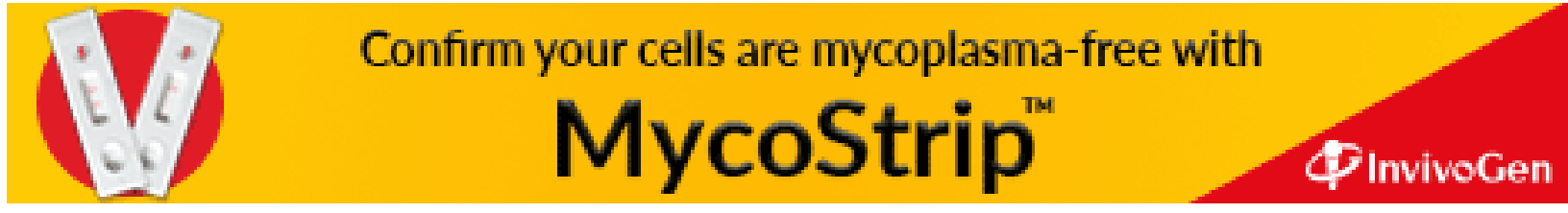

